\title{
Reporting postpartum haemorrhage with transfusion: a comparison of NSW birth and hospital data
}

\author{
Jillian A. Patterson ${ }^{\mathrm{A}, \mathrm{C}}$, Christine L. Roberts ${ }^{\mathrm{A}}$, \\ Lee K. Taylor ${ }^{\mathrm{B}}$ and Jane B. Ford ${ }^{\mathrm{A}}$ \\ ${ }^{\mathrm{A}}$ Clinical and Population Perinatal Health, Kolling Institute \\ of Medical Research \\ ${ }^{\mathrm{B}}$ Centre for Epidemiology and Evidence, NSW Ministry of Health \\ ${ }^{\mathrm{C}}$ Corresponding author.Email: jillian.patterson@sydney.edu.au
}

Abstract: Aim: Postpartum haemorrhage rates have been increasing in NSW and internationally, and blood transfusion is required in severe cases. Using routinely collected administrative data provides a convenient method with which to monitor trends in both postpartum haemorrhage and associated transfusion use. In order for this to be feasible however, the reliability of reporting of the conditions needs to be assessed. Methods: This study used linked data to compare the reporting of postpartum haemorrhage with transfusion as reported in the NSW Admitted Patient Data Collection (hospital data), with the same information obtained from the Perinatal Data Collection (birth data), for births in NSW from 2007 to 2010. Results: The rate of postpartum haemorrhage requiring blood transfusion was $1.0 \%$ based on the hospital data and $1.1 \%$ based on the birth data, with a rate of $1.7 \%$ if identifying cases from either source. Agreement between the two sources improved from fair to moderate over the time period. Conclusion: Postpartum haemorrhage requiring transfusion recorded in the birth data shows only moderate agreement with hospital data, so caution is recommended when using this variable for analysis. Linkage of both datasets is recommended to identify birth information from birth data and postpartum haemorrhage with transfusion from hospital data until further validation work has been undertaken.
An important application of population health data is identifying and monitoring trends in adverse outcomes which may require further investigation or intervention. ${ }^{1-3}$ In maternal health, one commonly monitored adverse outcome of childbirth is severe postpartum haemorrhage (PPH). Postpartum haemorrhage involves excessive blood loss post-childbirth, and affects about $6 \%$ of women in $\mathrm{NSW},{ }^{4}$ with rates increasing locally and internationally. ${ }^{5}$ Severity of PPH is commonly defined by quantity of blood lost, however this can be difficult to estimate, ${ }^{6}$ so blood product transfusion has become widely used as a marker of severe maternal morbidity associated with childbirth. In combination with routinely collected population data collections this marker has been used to monitor changes in morbidity over time, providing a timely and cost-effective way of monitoring trends. ${ }^{7,8}$ In order for a marker to be a good indicator of the health of the population it needs to be reported reliably and in a timely fashion. ${ }^{9-12}$

Currently, local studies reporting PPH requiring transfusion use hospital diagnosis and procedure codes recorded in hospital separation data. ${ }^{4}$ Ascertainment of both PPH (sensitivity $73.8 \%$, specificity $98.9 \%$ ) and transfusion (sensitivity $83.1 \%$, specificity $99.9 \%$ ) is relatively high, and the sensitivity of PPH in women requiring transfusion is $92.5 \%$ when compared with medical records. ${ }^{13}$ However, hospital data are not the best source of birth data. Identifying birth admissions from hospital records relies on the presence of a diagnosis code identifying a live or stillbirth, which differs in reliability when there are multiple births and according to birth outcome and has been shown to miss some births identified in legislated birth data. ${ }^{14,15}$ Additionally, hospital data lack detail on parity, gestation and obstetric history, which are important risk factors for PPH. Use of hospital records requires linkage to birth data to accurately identify hospitalisations related to a pregnancy or birth. This affects the timeliness of the data, with linked birth and hospital data available $12-18$ months later than birth data alone. Birth records, collected by midwives at the time of birth, are more timely, available after 12 months, and do not require linkage in order to identify births. Until recently, no data on blood transfusion was collected in these birth records. In 2007, New South Wales (NSW) birth data collections included a new variable 'PPH requiring transfusion'. The reliability of this variable has not yet been assessed. This project compared 


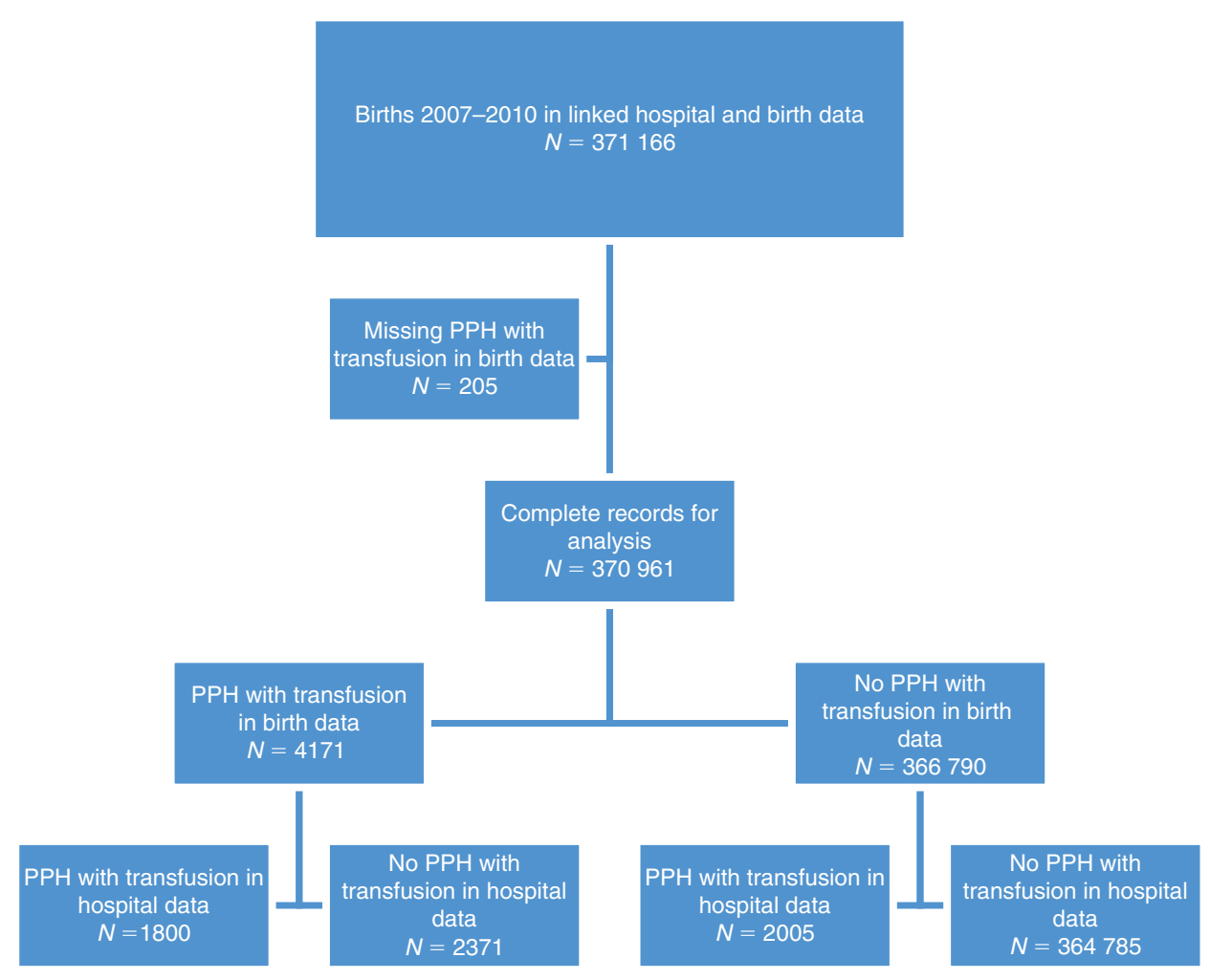

Figure 1. Study population for comparison of reporting of postpartum haemorrhage (PPH) with transfusion between birth and hospital data, NSW, 2007-2010. Source: New South Wales (NSW) Perinatal Data Collection and NSW Admitted Patient Data Collection, NSW Ministry of Health.

the reporting of PPH with blood transfusion in the hospital records to the new variable in the birth data.

\section{Methods}

Births were identified from the Perinatal Data Collection ('birth data'), a statutory collection of all births in NSW of at least 20 weeks gestation or $400 \mathrm{~g}$ birthweight. Hospital birth admissions were identified from the Admitted Patient Data Collection ('hospital data') which is a census of all public and private hospital separations in NSW, containing information on procedures and diagnoses, coded according to the 10th revision of the International Classification of Diseases, Australian Modification (ICD10-AM),${ }^{16}$ and the Australian Classification of Health Interventions. ${ }^{17}$ Probabilistic record linkage between the birth and hospital data was carried out by the NSW Centre for Health Record Linkage. All women giving birth in NSW hospitals from 1 January 2007 to 31 December 2010, where a corresponding hospital birth record was available, were included in this study.

The birth data, including demographic and medical information on the mother, as well as information on the labour, delivery and infant, is collected by the attending midwife or medical practitioner. $\mathrm{PPH}$ requiring transfusion is recorded if there was a "postpartum haemorrhage requiring transfusion of whole blood or packed cells". ${ }^{18}$ In the hospital data, blood transfusion was defined as a record of transfusion of packed cells or whole blood in any of the first 20 procedure codes in the maternal birth admission. Similarly, PPH according to the hospital data was defined as a diagnosis of PPH in any of the first 20 diagnosis fields. ${ }^{19}$ Hospitals were categorised by hospital type and annual number of deliveries (grouped to reflect similarity of practice by hospital size).

As neither hospital nor birth data could be considered a 'gold standard' for PPH with transfusion reporting, we assessed agreement based on kappa statistics, and compared characteristics of discordant cases. Kappa statistics were classified as follows: near perfect (0.81-1), excellent (0.61-0.80), moderate $(0.41-0.60)$, fair $(0.21-0.40)$, slight $(0.01-0.21)$ and no agreement $(<0.01){ }^{20}$

\section{Results}

From 2007 to 2010 there were 371166 births recorded in the linked hospital and birth data: $205(0.1 \%)$ were missing the birth data field for PPH requiring transfusion, leaving 370 961 births for analysis (Figure 1). Based on the hospital data the rate of $\mathrm{PPH}$ was $7.6 \%$, and the rate of transfusion of packed cells was $1.4 \%$. The rate of PPH with blood transfusion was $1.0 \%$ based on the hospital data and $1.1 \%$ according to the birth data (Table 1). In the hospital data, blood transfusion rates increased from $1.4 \%$ in 2007 to $1.5 \%$ in 2010 ( $p=0.006)$, $\mathrm{PPH}$ rates increased from $7.1 \%$ to $7.8 \%$ $(p<0.0001)$ and the combination of PPH with transfusion increased from $1.0 \%$ to $1.1 \%(p=0.02)$. In the birth data, 
Table 1. Concordance of postpartum haemorrhage (PPH) with transfusion cases identified from hospital data and birth data, NSW, 2007-2010

\begin{tabular}{|c|c|c|c|c|}
\hline & & \multicolumn{2}{|c|}{ Hospital data } & \multirow[b]{2}{*}{$\begin{array}{l}\text { Total } \\
n(\%)\end{array}$} \\
\hline & & $\begin{array}{l}\text { PPH with transfusion } \\
\text { recorded } \\
n(\%)\end{array}$ & $\begin{array}{c}\text { PPH with transfusion } \\
\text { not recorded } \\
n(\%)\end{array}$ & \\
\hline \multirow[t]{3}{*}{ Birth data } & PPH with transfusion recorded & $1800(0.5)$ & $2371(0.6)$ & $4171(1.1)$ \\
\hline & PPH with transfusion not recorded & $2005(0.5)$ & $364785(98.3)$ & $366790(98.9)$ \\
\hline & Total & $3805(1.0)$ & $367156(99.0)$ & $370961(100.0)$ \\
\hline
\end{tabular}

Table 2. Agreement in reporting of postpartum haemorrhage between birth data and hospital data, NSW, 2007-2010

\begin{tabular}{|c|c|c|}
\hline & Kappa $(95 \%$ Cl) & Agreement \\
\hline Overall & $0.45(0.43-0.46)$ & Moderate \\
\hline \multicolumn{3}{|l|}{ Mode of delivery } \\
\hline Vaginal & $0.44(0.43-0.46)$ & Moderate \\
\hline Caesarean & $0.45(0.43-0.47)$ & Moderate \\
\hline \multicolumn{3}{|l|}{ Year } \\
\hline 2007 & $0.37(0.34-0.39)$ & Fair \\
\hline 2008 & $0.36(0.33-0.39)$ & Fair \\
\hline 2009 & $0.44(0.41-0.47)$ & Moderate \\
\hline 2010 & $0.59(0.57-0.62)$ & Moderate \\
\hline \multicolumn{3}{|l|}{ Hospital type } \\
\hline Tertiary obstetric & $0.49(0.47-0.51)$ & Moderate \\
\hline Regional & $0.47(0.44-0.49)$ & Moderate \\
\hline Urban/other & $0.36(0.32-0.40)$ & Fair \\
\hline Private & $0.37(0.34-0.40)$ & Fair \\
\hline \multicolumn{3}{|c|}{ Annual delivery volume } \\
\hline 20-499 & $0.45(0.42-0.49)$ & Moderate \\
\hline 500-999 & $0.46(0.43-0.50)$ & Moderate \\
\hline $1000+$ & $0.44(0.43-0.46)$ & Moderate \\
\hline
\end{tabular}

PPH with transfusion increased from $1.2 \%$ to $1.3 \%$ ( $p=$ $0.03)$, despite lower rates in 2008-2009. When considering identification from either source, the rate of $\mathrm{PPH}$ with blood transfusion was $1.7 \%$. In hospitals with an average of over 50 births per year, the rates of women experiencing $\mathrm{PPH}$ with transfusion as recorded in the birth data ranged between $0.13 \%$ and $5.63 \%$, and in the hospital data between $0 \%$ and $2.31 \%$. The range of differences between birth data and hospital data was $-1.33 \%$ and $4.24 \%$ (data not shown). Sensitivity analysis was undertaken to determine if concordance differed between vaginal and caesarean births, however rates were similar (data not shown).

Overall, the PPH with transfusion as ascertained from the hospital and birth data had moderate agreement $(\mathrm{kappa}=0.45)($ Table 2$)$. Agreement tended to increase from 2007 to 2010 (Table 2). Twenty (17\%) of the 116 hospitals reported PPH with transfusion with near perfect agreement. The proportion of hospitals reporting near perfect agreement increased from $15 \%$ in 2007 to $31 \%$ in 2010, while those reporting fair agreement decreased from $30 \%$ in 2007 to $15 \%$ in 2010 . This increase in agreement was due to increased reporting in the birth data, with the proportion of PPH with transfusion identified in the hospital data alone decreasing from $33.3 \%$ in 2007 to $22.3 \%$ in 2010 , and those reported in both data sources increasing from $22.9 \%$ to $42.5 \%$ (Table 3 ).

PPH with transfusion was more likely to be reported only in the birth data than only in hospital data for primiparae (29.4\% vs $24.9 \%)$, pre-labour caesarean sections $(17.5 \%$ vs $11.8 \%)$ and for births in regional $(47.4 \%$ vs $9.7 \%)$ or private (31.5\% vs $8.4 \%$ ) hospitals (Table 3$)$, and less likely to be reported for multiple births $(2.7 \%$ vs $4.3 \%)$, caesarean section with labour (11.2\% vs $14.8 \%)$ and births at tertiary obstetric hospitals (13.9\% vs 63.3\%).

Of the 4171 women reported in the birth data to have had a PPH with transfusion, $68 \%$ of women were recorded in the hospital data as having a PPH, and 53\% were recorded in the hospital data as having received a blood transfusion. Both PPH and blood transfusion were recorded for $43.2 \%$ of these women (concordant cases). Further investigation of hospital data reporting indicated that $236(10.0 \%)$ of the 2371 discordant birth data records indicating a PPH with transfusion may have been for haematomas or antepartum/ intrapartum bleeding. Sixty-eight (2.9\%) records identified as PPH with transfusion in the birth data had a record of transfusion of another blood product recorded in the hospital data.

\section{Discussion}

We compared the new 'PPH requiring transfusion' variable reported in the birth data with the previously validated 'PPH with transfusion' variable from the hospital data and demonstrated moderate agreement. $\mathrm{PPH}$ with transfusion in the hospital data is known to have sensitivity of $92.5 \%{ }^{13}$ Assuming this rate of underreporting in the hospital data, having observed 3805 admissions with PPH and transfusion, we would expect the true number to be around 4114, resulting in a $\mathrm{PPH}$ with transfusion rate of $1.1 \%$. In the birth data we observed a rate of $1.1 \%$. As there is only 
Table 3. Characteristics of women with postpartum haemorrhage (PPH) with transfusion identified in either the birth data alone, hospital data alone, or both, NSW, 2007-2010

\begin{tabular}{|c|c|c|c|c|c|}
\hline & \multirow[b]{2}{*}{ Variable } & \multicolumn{3}{|c|}{ Source of identification of PPH with transfusion } & \multirow[b]{2}{*}{$p$-value } \\
\hline & & $\begin{array}{l}\text { Both } \\
n(\%)\end{array}$ & $\begin{array}{l}\text { Hospital data only } \\
n(\%)\end{array}$ & $\begin{array}{l}\text { Birth data only } \\
n(\%)\end{array}$ & \\
\hline Overall & & $1800(100.0)$ & $2005(100.0)$ & $2371(100.0)$ & \\
\hline \multicolumn{6}{|l|}{ Year $^{\mathrm{a}}$} \\
\hline & 2007 & $376(20.9,22.9)$ & $546(27.2,33.3)$ & $719(30.3,43.8)$ & $<.0001$ \\
\hline & 2008 & $335(18.6,22.7)$ & $556(27.7,37.6)$ & $589(24.8,39.7)$ & \\
\hline & 2009 & $432(24.0,28.6)$ & $559(27.9,37.0)$ & $519(21.9,34.4)$ & \\
\hline & 2010 & $657(36.5,42.5)$ & $344(17.2,22.3)$ & $544(22.9,35.2)$ & \\
\hline \multicolumn{6}{|c|}{ Age (years) } \\
\hline & $<20$ & $100(5.6)$ & $95(4.7)$ & $124(5.2)$ & 0.0371 \\
\hline & $20-24$ & $259(14.4)$ & $330(16.5)$ & $335(14.1)$ & \\
\hline & $25-29$ & $460(25.6)$ & $532(26.5)$ & $609(25.7)$ & \\
\hline & $30-34$ & $530(29.4)$ & $573(28.6)$ & $740(31.2)$ & \\
\hline & $35-39$ & $357(19.8)$ & $373(18.6)$ & $480(20.2)$ & \\
\hline & $40+$ & $94(5.2)$ & $102(5.1)$ & $83(3.5)$ & \\
\hline \multicolumn{6}{|c|}{ Multiple birth } \\
\hline & Yes & $78(4.3)$ & $87(4.3)$ & $63(2.7)$ & 0.003 \\
\hline & No & $1722(95.7)$ & $1918(95.7)$ & $2308(97.3)$ & \\
\hline \multicolumn{6}{|c|}{ Primiparae } \\
\hline & Yes & $468(26.0)$ & $500(24.9)$ & $696(29.4)$ & 0.0026 \\
\hline & No & $1332(74.0)$ & $1505(75.1)$ & 1675 (70.6) & \\
\hline \multicolumn{6}{|c|}{ Gestational age } \\
\hline \multirow[t]{3}{*}{ (weeks) } & $20-32$ & $77(4.3)$ & $82(4.1)$ & $67(2.8)$ & 0.0059 \\
\hline & $33-36$ & $142(7.9)$ & $159(7.9)$ & $149(6.3)$ & \\
\hline & $37+$ & $1560(86.7)$ & $1732(86.4)$ & $2130(89.8)$ & \\
\hline \multicolumn{6}{|c|}{ Delivery type } \\
\hline & Normal vaginal & $894(49.7)$ & $996(49.7)$ & $1238(52.2)$ & 0.1512 \\
\hline & Caesarean section (CS) (total) & $512(28.4)$ & $533(26.6)$ & $680(28.7)$ & 0.2586 \\
\hline & CS - No labour & $234(13.0)$ & $237(11.8)$ & 415 (17.5) & $<.0001$ \\
\hline & CS - Labour & $278(15.4)$ & $296(14.8)$ & $265(11.2)$ & $<.0001$ \\
\hline & Instrumental (total) & $404(22.4)$ & $472(23.5)$ & $465(19.6)$ & 0.0048 \\
\hline & Forceps & $198(11.0)$ & $222(11.1)$ & $192(8.1)$ & 0.0008 \\
\hline & Vacuum & $206(11.4)$ & $250(12.5)$ & $273(11.5)$ & 0.531 \\
\hline \multicolumn{6}{|c|}{ Private patient in public hospital } \\
\hline & Yes & $172(9.6)$ & $210(10.5)$ & $193(8.1)$ & 0.0275 \\
\hline & No & $1628(90.4)$ & $1795(89.5)$ & $2178(91.9)$ & \\
\hline \multicolumn{6}{|c|}{ Hospital type } \\
\hline & Tertiary obstetric & $779(43.3)$ & $1269(63.3)$ & $330(13.9)$ & $<.0001$ \\
\hline & Regional & $594(33.0)$ & $195(9.7)$ & $1125(47.4)$ & \\
\hline & Urban/other & $154(8.6)$ & $373(18.6)$ & $169(7.1)$ & \\
\hline & Private & $273(15.2)$ & $168(8.4)$ & $747(31.5)$ & \\
\hline \multicolumn{6}{|c|}{ Annual delivery volume } \\
\hline & $20-499$ & $256(14.2)$ & $51(2.5)$ & $551(23.2)$ & $<.0001$ \\
\hline & $500-999$ & $281(15.6)$ & $126(6.3)$ & $521(22.0)$ & \\
\hline & $1000+$ & $1263(70.2)$ & $1828(91.2)$ & $1293(54.5)$ & \\
\hline
\end{tabular}

${ }^{a}$ Column (first) and row (second) percentages are presented. All other reported percentages are column percentages.

Source: New South Wales (NSW) Perinatal Data Collection and NSW Admitted Patient Data Collection, NSW Ministry of Health.

moderate agreement observed between the two sources, however, considering identification from either source (1.7\%) would lead to a possible $55 \%$ overestimation. We also noted an increase in reliability of the birth data in later years. This was associated with improved reliability in a small number of hospitals, particularly in hospitals with a research interest around postpartum haemorrhage or transfusion. 
Differences in the collection of data may explain some of the variation. Birth data is collected by the midwives and clinicians attending the birth, with the variable ' $\mathrm{PPH}$ requiring transfusion' being recorded as a check box on an electronic data entry form. In the hospital data, both transfusion and PPH are coded by hospital coders based on notes written in the medical record. PPH can only be coded from the medical record if it is specifically written as such in the notes.

The lower reporting of PPH with transfusion in birth data following more complex birth situations (multiple births, after caesarean section following labour, and at tertiary obstetric facilities) may be related to differences in data recording. Obstetric staff compiling birth data may not have details available of events occurring outside the labour ward, whereas medical coding departments may have additional information from operation reports. Validation studies have demonstrated that birth data more accurately report labour and delivery factors than subsequent events, ${ }^{9}$ and that procedures (e.g. transfusion) are well ascertained in hospital data. ${ }^{9}$

Some of the discordant records may relate to misclassification of transfusion type or timing. A French study compared the reporting of transfusion in a birth database with records from the blood bank, ${ }^{21}$ treating the blood bank data as the gold standard, finding sensitivity of $61.4 \%$, and positive predictive value of $82.2 \%$, with kappa 0.7 . In their study, birth records misclassified as blood transfusion were typically transfusion of another blood product (other than red cells) or other product for bleeding. This was also the case in our study. In the French study, transfusions not recorded in the birth record were for transfusions outside of the obstetric department (intensive care unit, during transfers between hospitals) or were miscoding. Importantly, the birth data imply that a transfusion occurred posthaemorrhage, however the timing of diagnoses and procedures recorded in the hospital data cannot be ascertained. It is possible that some of the transfusions recorded in the hospital data occurred for antepartum rather than postpartum haemorrhage. An earlier study using NSW hospital data indicated that $75 \%$ of obstetric transfusions were for postpartum haemorrhage and a further $8 \%$ were for antepartum haemorrhage (occurring prior to birth) ${ }^{22}$

Population health datasets can provide a rich source of data for research, but their usefulness is limited by the quality of the data they contain. ${ }^{10-13}$ Previous studies have shown that accepting diagnoses from more than one data source can increase ascertainment, without increasing false positives, ${ }^{10,23,24}$ however this is not always the case, and this study suggests that identifying PPH with transfusion from either birth or hospital data would result in overascertainment of around $55 \%$.

This study used one dataset (hospital data) to validate another dataset (birth data). While this allows for an initial assessment of the reliability of the birth data variable, an ideal assessment would have been to use a 'gold standard' such as medical record review for validation. However, such validation studies are resource intensive and difficult to justify for single, relatively rare outcomes. Previous validation studies have shown that PPH and transfusion are underreported in the hospital data. ${ }^{13}$

\section{Conclusion}

We have shown that the new variable 'PPH requiring transfusion' being collected on the birth data shows only moderate agreement with hospital data. We would therefore recommend that researchers use the birth data variable with caution until further validation has been undertaken. Where possible, birth data linked with hospital data can be used to identify PPH with transfusion. An advantage of this approach is that, although there is some under-ascertainment, these data have already been validated. The changes in ascertainment over time in the birth data indicate that early years of data collected on PPH requiring transfusion should be excluded from trend analysis, to prevent improved ascertainment being interpreted as a change in incidence.

\section{Acknowledgments}

Jillian Patterson was supported by a National Health and Medical Research Council (NHMRC) Partnership Grant (\#1027262). Christine Roberts is supported by a NHMRC Senior Research Fellowship (\#1021025). Jane Ford is supported by an Australian Research Council Future Fellowship (\#120100069). We thank the NSW Ministry of Health for access to the population health data and the NSW Centre for Health Record Linkage for linking the datasets.

\section{References}

1. Callaghan WM, Mackay AP, Berg CJ. Identification of severe maternal morbidity during delivery hospitalizations, United States, 1991-2003. Am J Obstet Gynecol 2008; 199(2): 133. doi:10.1016/j.ajog.2007.12.020

2. Joseph KS, Rouleau J, Kramer MS, Young DC, Liston RM, Baskett TF. Investigation of an increase in postpartum haemorrhage in Canada. BJOG 2007; 114(6): 751-9. doi:10.1111/ j.1471-0528.2007.01316.x

3. Kuklina EV, Meikle SF, Jamieson DJ, Whiteman MK, Barfield WD, Hillis SD et al. Severe obstetric morbidity in the United States: 1998-2005. Obstet Gynecol 2009; 113: 293-9. doi:10.1097/AOG.0b013e3181954e5b

4. Ford JB, Roberts CL, Simpson JM, Vaughan J, Cameron CA. Increased postpartum hemorrhage rates in Australia. Int $J$ Gynaecol Obstet 2007; 98(3): 237-43. doi:10.1016/ j.ijgo.2007.03.011

5. Knight M, Callaghan WM, Berg C, Alexander S, Bouvier-Colle $\mathrm{MH}$, Ford JB et al. Trends in postpartum hemorrhage in high resource countries: a review and recommendations from the International Postpartum Hemorrhage Collaborative Group. BMC Pregnancy Childbirth 2009; 9: 55. doi:10.1186/14712393-9-55

6. Stafford I, Dildy GA, Clark SL, Belfort MA. Visually estimated and calculated blood loss in vaginal and cesarean 
delivery. Am J Obstet Gynecol 2008; 199(5): 519. doi:10.1016/ j.ajog.2008.04.049

7. Quan H, Parsons GA, Ghali WA. Validity of procedure codes in International Classification of Diseases, 9th revision, clinical modification administrative data. Med Care 2004; 42(8): 801-9. doi:10.1097/01.mlr.0000132391.59713.0d

8. Singleton S. Data sources and performance measurement. BMJ 2007; 335(7623): 730. doi:10.1136/bmj.39356.610544.BE

9. Lain SJ, Hadfield RM, Raynes-Greenow CH, Ford JB, Mealing NM, Algert CS et al. Quality of data in perinatal population health databases: a systematic review. Med Care 2012; 50(4): e7-20. doi:10.1097/MLR.0b013e31821d2b1d

10. Lydon-Rochelle MT, Holt VL, Nelson JC, Cárdenas V, Gardella C, Easterling TR et al. Accuracy of reporting maternal in-hospital diagnoses and intrapartum procedures in Washington State linked birth records. Paediatr Perinat Epidemiol 2005; 19(6): 460-71. doi:10.1111/j.1365-3016.2005.00682.x

11. Schoendorf KC, Branum AM. The use of United States vital statistics in perinatal and obstetric research. Am JObstet Gynecol 2006; 194(4): 911-5. doi:10.1016/j.ajog.2005.11.020

12. Yasmeen S, Romano PS, Schembri ME, Keyzer JM, Gilbert WM. Accuracy of obstetric diagnoses and procedures in hospital discharge data. Am J Obstet Gynecol 2006; 194(4): 992-1001. doi:10.1016/j.ajog.2005.08.058

13. Lain SJ, Roberts CL, Hadfield RM, Bell JC, Morris JM. How accurate is the reporting of obstetric haemorrhage in hospital discharge data? A validation study. Aust N Z J Obstet Gynaecol 2008; 48(5): 481-4. doi:10.1111/j.1479-828X.2008.00910.x

14. Bentley JP, Ford JB, Taylor LK, Irvine KA, Roberts CL. Investigating linkage rates among probabilistically linked birth and hospitalization records. BMC Med Res Methodol 2012; 12: 149. doi: $10.1186 / 1471-2288-12-149$

15. Taylor LK, Travis S, Pym M, Olive E, Henderson-Smart DJ. How useful are hospital morbidity data for monitoring conditions occurring in the perinatal period? Aust $N Z J$ Obstet
Gynaecol 2005; 45(1): 36-41. doi:10.1111/j.1479828X.2005.00339.X

16. National Centre for Classification in Health. Tabular list of diseases ICD 10 AM. Sydney: National Centre for Classification in Health; 2006.

17. National Centre for Classification in Health. Australian classification of Health Interventions. Sydney: National Centre for Classification in Health; 2006.

18. New South Wales Perinatal Data Collection Manual. 2011 Edition. Available at: http://www0.health.nsw.gov.au/ resources/publichealth/mph/pdc_manual_2011.asp (Cited 23 January 2014).

19. Patterson JA, Roberts CL, Bowen JR, Irving DO, Isbister JP, Morris JM et al. Blood transfusion during pregnancy, birth and the postnatal period. Obstet Gynecol 2014; 123(1): 126-33. doi:10.1097/AOG.0000000000000054

20. Landis JR, Koch GG. The measurement of observer agreement for categorical data. Biometrics 1977; 33(1): 159-74. doi: $10.2307 / 2529310$

21. Sagot P, Mourtialon P, Benzenine E, Bardou M, Ferdynus C, Morel $\mathrm{P}$ et al. Accuracy of blood transfusion in postpartum hemorrhage to assess maternal morbidity. Eur J Obstet Gynecol Reprod Biol 2012; 162(2): 160-4. doi:10.1016/j. ejogrb.2012.02.021

22. Roberts CL, Ford JB, Thompson JF, Morris JM. Population rates of haemorrhage and transfusions among obstetric patients in NSW: a short communication. Aust NZ J Obstet Gynaecol 2009; 49(3): 296-8. doi:10.1111/j.1479-828X.2009.00985.x

23. Callaghan WM, Kuklina EV, Berg CJ. Trends in postpartum hemorrhage: United States, 1994-2006. Am J Obstet Gynecol 2010; 202(4): 353. doi:10.1016/j.ajog.2010.01.011

24. Roberts CL, Bell JC, Ford JB, Morris JM. Monitoring the quality of maternity care: how well are labour and delivery events reported in population health data? Paediatr Perinat Epidemiol 2009; 23(2): 144-52. doi:10.1111/j.1365-3016.2008.00980.x 